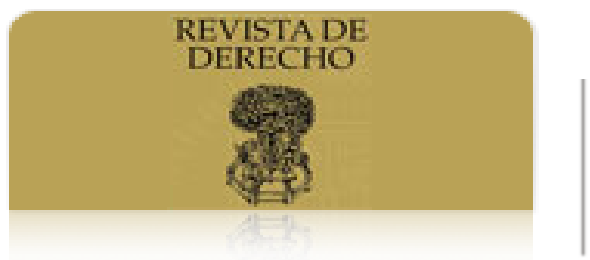

\author{
Revista de Derecho (Valparaiso) \\ ISSN: 0716-1883 \\ dirder@ucv.cl \\ Pontificia Universidad Católica de \\ Valparaíso \\ Chile
}

Barroilhet Acevedo, Claudio

Embargos comerciales en el transporte marítimo

Revista de Derecho (Valparaiso), núm. XLIII, julio-diciembre, 2014, pp. 39-75

Pontificia Universidad Católica de Valparaíso

Valparaíso, Chile

Disponible en: http://www.redalyc.org/articulo.oa?id=173636985001

- Cómo citar el artículo

- Número completo

- Más información del artículo

- Página de la revista en redalyc.org

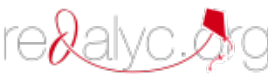

Sistema de Información Científica

Red de Revistas Científicas de América Latina, el Caribe, España y Portugal Proyecto académico sin fines de lucro, desarrollado bajo la iniciativa de acceso abierto 


\title{
EMBARGOS COMERCIALES EN EL TRANSPORTE MARÍTIMO
}

[Trade Embargoes in Maritime Carriage]

\author{
Claudio Barroilhet Acevedo* \\ Pontificia Universidad Católica de Valparaíso, Chile
}

\begin{abstract}
RESUMEN
El embargo comercial es una prohibición de comerciar con determinados Estados o zonas, que decreta otro Estado, sus gobernantes o una autoridad supranacional, y que afecta desde luego al transporte marítimo de mercancías, pero también a otras figuras del derecho de la navegación, como el caso fortuito (con diversas denominaciones en lengua inglesa), que son el objeto de análisis de este artículo.

\section{Palabras clave}

Embargo - Bloqueo - Boicot - Arraigo de naves - Retención de mercaderías Requisición - Confiscación - Represalia - Presa - Caso fortuito.
\end{abstract}

\begin{abstract}
Trade embargo is the prohibition of trading with determined States or zones, ordered by other State, of course, affecting the sea carriage of goods, but also other concepts of the navigation acts, such as Act of God (with various names in the English language), which are analysed in this article.

\section{KEYWORDS}

Embargo - Blockade - Boycott - Arrest of vessels - Seizure of merchandise Requisition - Confiscation - Retaliation - Detained - Act of God.
\end{abstract}

RECIBIDO el 13 de septiembre y ACEPTADO el 25 de noviembre de 2014

* Abogado, LL.M. Admiralty Law, Tulane University, U.S.A., profesor de derecho marítimo de la Facultad de Derecho de la Pontificia Universidad Católica de Valparaíso. Correo postal: Av. Brasil 2950, Valparaíso, Chile. Correo electrónico:cbarroilhet@ csav.com 


\section{Presentación}

Los embargos son prohibiciones de comerciar con determinados Estados o zonas, y como tales han existido desde los tiempos inmemoriales en el comercio internacional, y por ende afectan al transporte marítimo de mercancías, que es la principal vía a través de la cual dicho intercambio se efectúa. En un mundo globalizado como el actual, en que existen cruzadas internacionales en contra del terrorismo, o de la proliferación de armas nucleares, o para defender la vida, integridad personal y libertades básicas de las personas, han aumentado los embargos como mecanismo de presión o represión internacional en contra de determinados Estados.

El objetivo de este artículo es identificar los elementos que configuran un embargo, diferenciarlo de instituciones similares como bloqueo, boicot o apresamiento, y desentrañar su naturaleza jurídica y configuración con instituciones como la fuerza mayor, caso fortuito ("act of God", "act of princess", etc.

Una vez identificados sus confines y diferenciado de las figuras que se le asimilan o relacionan, se procede a explicar su interacción y efectos en distintas instituciones del transporte marítimo, como los contratos de fletamento y transporte de mercancías por mar, en los riesgos de la navegación y en los seguros marítimos.

Es importante consignar que el embargo internacional acarrea efectos no sólo en el transporte marítimo, sino que también en una serie de contratos e instituciones que se relacionan al mismo, cual es el caso de la compraventa internacional, los créditos documentarios y las pólizas de seguros. En este artículo nos limitaremos a analizar aquellas figuras e instituciones puramente marítimas.

\section{ElEMENTOS DEL EMBARGo COMERCIAL}

En términos simples, un embargo es una prohibición que dicta una autoridad para comerciar con un determinado país o zona, fundado en razones políticas, económicas o bélicas.

Sus elementos integrantes son:

i) Una prohibición de comerciar, esto es, una interdicción o restricción absoluta para intercambiar bienes y servicios, o efectuar negocios con un Estado o una zona determinada. Esta prohibición puede afectar a todo tipo de mercancías, bienes y servicios, o sólo algunas, como las armas, los combustibles o sus derivados, etc.

ii) Debe emanar de una autoridad, que generalmente es un Estado, o una autoridad supra o internacional. Ejemplo de una autoridad nacional es 
Aduanas o las entidades nacionales que regulan el comercio internacional; ejemplo de una autoridad supra-nacional son los organismos de la Unión Europea y ejemplo de una autoridad internacional es el Consejo de Seguridad de las Naciones Unidas (u otro de sus organismos).

En el derecho inglés, se utiliza la expresión "arrest or restraint of princess", "rulers and people", que se define como "interferencias por la fuerza de un Estado, gobierno o país, tomando posesión de las mercancías por un acto de coerción ${ }^{1}$, como los arrestos, embargos, bloqueos, por causas de conformidad con el derecho común, como en los casos de negociaciones con el enemigo después de desatada una guerra, y a los actos de gobierno que se funden en otros propósitos, resultantes indirectamente en la detención de los bienes"2.

Si esta prohibición emana de un grupo de personas que no sean una autoridad, podría configurarse un boicot o un bloqueo. En el derecho inglés, así como en las "Reglas de La Haya", se utiliza la expresión "rulers", que equivaldría a los conductores o gobernantes, sin atender a la legitimidad de su autoridad, sea en su origen o ejercicio. Esto es importante, porque permitiría incluir a los gobernantes de facto, tales como los dictadores.

iii) Debe estar destinado a un Estado, región o zona que es distinta de aquella que dicta la orden, o sea, la orden debe estar dirigida y afectar a un tercer país, puesto que si sólo se aplica dentro del territorio del Estado o zona en la que la autoridad que dicta la orden ejerce su jurisdicción, se trata de una regulación económica o aduanera que es propia del orden interno de aquel Estado o zona, pero no importa un embargo o prohibición respecto de otro Estado.

Así sucede, por ejemplo, con la prohibición de internar vehículos motorizados usados que impera en nuestro país, o con las regulaciones y restricciones al comercio, porte y tráfico de armas, fármacos, medicamentos, etc., con las prohibiciones de importar en general y las prohibiciones de descargar, que no tengan su antecedente en un embargo internacional.

iv) Y debe consistir en una represalia o sanción ${ }^{3}$, que se fundamenta en razones políticas, económicas o bélicas, que sean esgrimidas como justifi-

${ }^{1}$ Los ingleses utilizan la expresión "strong hand”, que literalmente se traduce como la "mano dura o fuerte", para mentar al acto de autoridad, como una manifestación de fuerza o poder, en que no basta que la decisión emane de la autoridad, sino que además se trata de un acto coactivo, que se efectúa por medio de la fuerza o del poder.

${ }^{2}$ Boyd, Stewart - Berry, Steven - Burrows, Andrew - Eder, Bernard - Foxton David - Smith, Christopher, Scrutton on Charter Parties and Bills of Lading (21 ${ }^{\mathrm{a}}$ edición, London, Sweet \& Maxwell, 2008), p. 202.

${ }^{3}$ Los objetivos de las sanciones pueden ser coaccionar el cumplimiento o la cooperación con las medidas decretadas de acuerdo al Derecho Internacional (por ejemplo, en 1990, las Naciones Unidas adoptan una serie de sanciones para disuadir a Iraq de invadir a Kuwait), para asegurar la paz dentro de determinados zonas (resolución del 
cación para imponer la restricción (prescindiendo si la justificación tiene o no asidero en la realidad y en las regulaciones imperantes). Este elemento es importante para diferenciar al embargo de otras figuras similares, como la cuarentena o las restricciones fitosanitarias, en que la prohibición de ingresar mercancías o productos a un determinado Estado se justifican en razones de salud o de higiene públicas.

La combinación de los dos últimos elementos del embargo: que se dirija y afecte a un tercer Estado o zona (distinto del Estado que la decreta), y que se funde en razones políticas, económicas o bélicas, transforma a esta figura en controvertida o discutible, desde el punto de vista del derecho internacional público, dado que está destinada a producir efectos extraterritoriales, fuera del territorio del Estado del cual proviene la orden, afectando a otros territorios o zonas, sobre las cuales el Estado que lo decreta no ejerce soberanía, de manera que se violenta la soberanía e independencia de un Estado distinto. Por esto, históricamente, se lo considera un acto hostil, de guerra.

Precisamente, el objetivo del embargo es bloquear y aislar a la zona afectada por él, privándola de uno o más productos o mercancías, sea con el objeto de desabastecerla y generar estragos en su población, para dañarla política y económicamente, como sucede en los embargos de alimentos y mercancías necesarias para la subsistencia. Uno de los embargos más completos y sostenidos es el embargo de los Estados Unidos de Norteamérica en contra de Cuba, de carácter comercial, económico y financiero, que data desde febrero de 1960, originado a título de represalia por las expropiaciones del gobierno de Fidel Castro a propiedades de ciudadanos y compañías estadounidenses en la isla. El año 1992, con la emisión de la Cuban Democracy Act, el embargo se pasó a fundamentarse en la falta de democracia y respeto a los derechos humanos que existía en la isla. En 1996, la Helms-Burton Act amplió el embargo para proscribir los negocios de los ciudadanos estadounidenses dentro de la isla y con el gobierno de Cuba. En 1999 se amplió más aún, prohibiendo a las filiales extranjeras de empresas norteamericanas comerciar con Cuba por valores superiores a 700 millones de dólares anuales.

También existen embargos parciales, que abarcan sólo determinadas mercancías o productos, por ejemplo, embargo de armas, que prohíbe la comercialización de estos elementos (sus accesorios y equivalentes), fundado en represalia a actos de guerra u hostiles del Estado o zona afectada, o como una medida de prevención o contención destinada a evitar que este Estado adquiera un poder bélico excesivo, que altere los equilibrios existentes con sus vecinos, o que pueda ser considerado riesgosos en manos de gobernantes

año 2010 que condenan el uso de armas nucleares en Irán) y aquellas que condenan actos específicos en contra de la paz. 
proclives a la guerra o que puedan ser incontrolables. Así sucede, por ejemplo, en el caso de Irán, con el embargo de armas, petróleo, gas, y de actividades de la industria bancaria, aseguradora y marítima, impuesto en septiembre de 2006 por las Naciones Unidas y la Unión Europea. Un ejemplo es el embargo de armas y de bienes de lujo a Corea del Norte, decretado también por aquellas entidades en noviembre de 2006.

Otro caso de un embargo parcial fue el decretado por las Naciones Unidas en contra de Sud África, en noviembre de 1987, respecto del comercio y transporte de petróleo, en represalia a las políticas de "apartheid" adoptadas en este país, medida que contó con la adhesión voluntaria de 130 Estados.

\section{EMBARGO COMERCIAL Y OTRAS FIGURAS MÁS O MENOS EQUIVALENTES}

Con el propósito de complementar la tarea de definir al embargo comercial, procederemos a compararlo con otras figuras similares o relacionadas.

\section{Embargo y cuarentena.}

Cuarentena es una prohibición de transferencia o flujo de personas, animales, vegetales, alimentos y otros productos de consumo humano, vegetal o animal, que se fundamenta en razones de higiene y salud, para evitar el contagio de plagas u otras enfermedades.

La cuarentena es un clásico ejemplo de hecho de la autoridad, también denominada retención, detención o embargo por soberanos, autoridades o pueblos, que constituyen "actos de coacción por parte del poder público, que impiden el viaje" ${ }^{\prime}$, sea porque la nave o la carga a transportar no pueden utilizarse en su prosecución, producto de un mandato legal, o los titulares de ellas, son privados de sus derechos de dominio y uso de las mismas, haciéndose imposible concluir el viaje, o se prohíbe descargar las mercancías, una vez arribadas al puerto de destino. Como es un acto de la autoridad, configura un caso fortuito o fuerza mayor, de acuerdo con el artículo 45 CC.

La cuarentena, al igual que la prohibición de comerciar o embargo, son ordenes de autoridad que restringen el uso o privan de la propiedad de las cosas afectadas, como la nave o la carga, es decir, tienen en común su origen y su finalidad y naturaleza jurídica: ambas son una orden de la autoridad, que restringe o priva de la propiedad. Además, ambas comparten el carácter de represalia, sea como una medida de reacción (en el caso de la cuarentena)

${ }^{4}$ Ruiz Soroa, José María - Zabaleta, Santiago - González, Manuel, Manual de derecho del transporte maritimo (Vitoria-Gasteiz, 1986), p. 428. 
o una medida punitiva o de retaliación (como en el embargo), pero ambas son reacciones a un evento previo o inminente.

La diferencia entre ellas radica en la razón que las explica, en el caso de la cuarentena hay razones de salud e higiene, que son asuntos de público interés, en los que las autoridades sanitarias, de salud y aduaneras están investidas del poder para restringir las actividades de los particulares, estableciendo prohibiciones de comerciar, cargar, descargar, almacenar, manipular o portar ciertas mercancías, o respecto de una nave, estableciendo su aislamiento o la confiscación de mercancías u objetos contaminados, o que afecten a determinadas personas, disponiendo su aislamiento 5 .

Por su parte, el embargo comercial internacional es una prohibición que se funda en razones económicas, políticas o bélicas, y generalmente produce efectos extra-territoriales, a diferencia de la cuarentena, que en principio se restringe al territorio nacional.

En el derecho inglés, las regulaciones de cuarentena se consideran un caso de "restrain of princess". El clásico caso de cuarentena es "Miller v. Law Accident Insurance Co." ${ }^{\prime}$, de un embarque de ganado desde Liverpool a Buenos Aires, en que al momento del embarque de las cabezas en el puerto de origen, en Buenos Aires regía una orden de la autoridad que prohibía importar animales infectados, o desde lugares infectados. A su llegada a destino, los animales fueron inspeccionados y encontrados enfermos, decretándose su expulsión del país. El ganado fue reexpedido hacia Montevideo, donde se internó. La corte estimó que la pérdida del ganado transportado constituía

${ }^{5}$ Dispone el artículo 174 del Código Sanitario chileno: "La infracción de cualquiera de las disposiciones de este Código o de sus reglamentos y de las resoluciones que dicten los Directores de los Servicios de Salud o el Director del Instituto de Salud Pública de Chile, según sea el caso, salvo las disposiciones que tengan una sanción especial, será castigada con multa de un décimo de unidad tributaria mensual hasta mil unidades tributarias mensuales. Las reincidencias podrán ser sancionadas hasta con el doble de la multa original. Las resoluciones que establezcan las infracciones y determinen las multas tendrán mérito ejecutivo y se harán efectivas de acuerdo con los artículos 434 y siguientes del Código de Procedimiento Civil. Las infracciones antes señaladas podrán ser sancionadas, además, con la clausura de establecimientos, recintos, edificios, casas, locales o lugares de trabajo donde se cometiere la infracción; con la cancelación de la autorización de funcionamiento o de los permisos concedidos; con la paralización de obras o faenas; con la suspensión de la distribución y uso de los productos de que se trate, y con el retiro, decomiso, destrucción o desnaturalización de los mismos, cuando proceda".

${ }^{6}$ Colinvaux, Raoul, Carver's Carriage by Sea (12a edición, London, Steven \& Sons, 1971), I, p. 150; Boyd, St. y otros, Scrutton on Charter Parties, cit. (n. 2), p. 202.

${ }^{7}$ (1903) 1 K B 712, citado por Colinvaux, R., Carver's Carriage, cit. (n. 6), I, p. 154. 
un "restrain of princess", y por ende estaba cubierto en la póliza de seguro de la mercancía.

\section{Embargo y bloqueo.}

Un bloqueo es una interrupción del flujo de alimentos, provisiones, armas y otros productos necesarios para subsistir o defenderse, incluyendo las comunicaciones y el traspaso de personas y objetos a través de sus fronteras. La diferencia con el embargo es que el bloqueo es una medida de facto, propia de la guerra, fundamentada en razones bélicas o políticas, y no es propia de los tiempos de paz, como lo es el embargo. El bloqueo adopta la forma de un sitio a los puertos, aeropuertos o fronteras terrestres de la zona afectada por la medida. Uno de los ejemplos históricos de bloqueo ocurrió durante las guerras napoleónicas, a fines del siglo XVIII, y fue impuesto por Napoleón Bonaparte en contra del Reino Unido, proscribiendo a las naciones europeas de comerciar con la isla, sin mayor éxito, por cuanto perjudicó más a las naciones continentales que a los británicos. Otro ejemplo es el embargo de Cuba, que los cubanos consideran un bloqueo, no sin justa razón, al menos durante el período que comprende entre 1960 y 1992, fecha en que se dictó la Cuban Democracy Act.

Con todo, es posible concebir que existan bloqueos que tengan como antecedente un embargo.

\section{Embargo y boicot.}

El boicot constituye una medida de facto, consistente en la abstención voluntaria de usar, consumir o comerciar con una zona o Estado determinado, o con una o más personas u organizaciones, a título de protesta o represalia por razones sociales o políticas. Ejemplos de boicot son el de los Estados Unidos de Norteamérica en contra de las Olimpíadas de Verano en Moscú (1980), y el boicot soviético a las Olimpíadas de Verano en Los Ángeles (1984).

\section{Embargo y otras represalias internacionales.}

Otros tipos de represalias internacionales que pueden adoptarse contra un Estado son las diplomáticas, como la reducción o remoción de los vínculos consulares o diplomáticos; sanciones económicas, como el embargo de una o más mercancías, productos o servicios; sanciones militares, como la invasión o intervención armada, y sanciones deportivas, como la prohibición de que sus equipos nacionales compitan en eventos internacionales.

\section{Embargo comercial y embargo judicial.}

La prohibición de comerciar es distinta al embargo decretado en un juicio ejecutivo (individual o concursal), al arraigo de una nave en un procedimiento 
cautelar, a la retención judicial decretada judicialmente, a la prohibición de celebrar actos o contratos ordenada por un juez (aun sin una incautación o retención material de la cosa por ella afectada), ni a los procedimientos judiciales, o sus efectos, o a una orden judicial que pueda hacerse efectiva en el puerto de recalada respecto de la carga, por hechos anteriores al viaje. Se incluyen asimismo los procedimientos criminales, que conlleven la retención, incautación, decomiso o comiso de la nave o la carga, sea como una medida precautoria mientras se investiga, o como una pena decretada judicialmente.

En todas estas situaciones, así como en las medidas precautorias ("injuctions", "attachments", actio in rem, actio in personam), arrestos, y aún en los “possesory liens", existe un derecho o una pretensión que se invoca en contra de la persona del armador o naviero (o del propietario de la nave, transportador, operador, administrador, etc.) o de la mercancía a trasportar, que se canaliza y deriva en un procedimiento judicial y una orden de inmovilizar o retener la nave o la carga concretas, pero ello no constituye propiamente una orden de la autoridad que prohíba comerciar con esa nave o mercancía, sino que al resultado de una acción judicial de terceros hacia una de las partes de la aventura marítima, que generalmente se funda en el ejercicio de la garantía patrimonial por parte de sus acreedores.

Siguiendo a Carver, digamos que "cuando las mercancías han sido sacadas del buque en virtud de un procedimiento ante un tribunal del puerto, a instancias de alguien que reclama un derecho sobre ellos, eso no es un acto de la autoridad que quepa dentro de la excepción. Por lo mismo, la excepción no cubre la responsabilidad del propietario o armador ante los embarcadores, si la nave ha sido arraigada, por ejemplo, por los fletadores. "Restrain of princess and rulers" es el acto de un Estado o gobierno que interfiere con mano dura, y no la resolución de algún tribunal"8.

Así, la orden de autoridad que se contiene en la resolución judicial que ordena privar de la propiedad o del uso de la nave o la mercancía a transportar, no constituye un acto de autoridad o "restraint of princess", que sea coercitivo, o en que se ejerza una mano dura, como sí sucede en el embargo o prohibición de comerciar. En "Finlay v. Liverpool and G.W. Co." (1870)", se consideró que las mercancías retenidas a virtud orden de una Corte Civil del Estado de Nueva York, en una acción civil, no constituían un embargo en los términos de la excepción "restraint of princess"10.

${ }^{8}$ Colinvaux, R., Carver's Carriage, cit. (n. 6), I, p. 152.

${ }^{9}$ Citado por Boyd, St. y otros, Scrutton on Charter Parties, cit. (n. 2), p. 204.

${ }^{10}$ Este precedente se repite en varios casos, en 1806, 1809, 1872, 1896, 1900 y 1916, citados por Colinvaux, R., Carver's Carriage, cit. (n. 6), I, p. 152; y por Boyd, St. y otros, Scrutton on Charter Parties, cit. (n. 2), p. 204.

${ }^{10}$ Citado por Boyd, St. y otros, Scrutton on Charter Parties, cit. (n. 2), p. 204. 
En este mismo sentido, en el First Schedule de la Marine Insurance Act de 1906, la regla de interpretación $\mathrm{N}^{\circ} 10$ establece que "Limitación del príncipe. El término 'arrestos del rey, príncipe y de la gente' se refiere a actos políticos o del ejecutivo, y no incluye a una pérdida causada por revueltas o por procesos judiciales ordinarios".

\section{Embargo, arraigo de naves y retención de mercancias transportadas.}

Constituyen casos de procedimientos judiciales marítimos, que pueden recaer sobre la nave y la mercancía transportada o por transportarse en ella y que, atendida su especialidad, analizaremos por separado del denominado embargo judicial.

El artículo $1231 \mathrm{CCom}$. permite al titular de un crédito privilegiado sobre una nave, solicitar al tribunal civil (de turno del lugar donde aquélla se encuentre, o que fuere competente según las normas de este libro) que se prohíba el zarpe de aquélla, para garantizar el ejercicio del crédito privilegiado o asegurar el cumplimiento de una decisión judicial que pueda implicar la realización de la nave afectada. Esto inicia el procedimiento de arraigo de naves y puede llevar a la realización judicial de la nave.

El artículo 1232 CCom. aclara que los términos prohibición de zarpe, retención, arraigo e inmovilización, se consideran sinónimos, pero no comprenden al embargo de una nave decretado en procedimientos de apremio, que corresponde al embargo judicial antes explicado.

Por su parte, el artículo 861 del mismo cuerpo legal, enumera ciertos créditos que gozan de privilegio sobre las mercancías y concurrirán sobre su valor de realización. Enseguida, el artículo 865 CCom. concede al fletante o transportador el derecho de solicitar al juez competente del puerto de descarga que tales mercancías sean depositadas en poder de un tercero para su realización, en la proporción que fuere necesaria para satisfacer los créditos privilegiados que las gravan. Agrega que la realización se hará conforme a las reglas que para los bienes muebles establece el título I del libro III del Código de Procedimiento Civil.

Como se dijo, estos son casos de procedimientos judiciales especiales, que pertenecen a la familia de los embargos judiciales, que son figuras distintas al embargo comercial, interdicción o prohibición de comercio, ni constituyen eventos de casos fortuitos o fuerza mayor. Y tratándose de procedimientos judiciales, como apunta Ruiz Soroa "el embargo judicial ("seizure under legal process") debe ser, para poder funcionar como causa de exoneración, injustificado e independiente de toda culpa del porteador o sus dependientes. Un buque arrestado debido a deudas de anteriores viajes entraña un supuesto de innavegabilidad"11.

\footnotetext{
${ }^{11}$ Ruiz SoroA, J. M., y otros, cit. (n. 4), p. 428.
} 


\section{Embargo y expropiación.}

La expropiación también constituye un acto de la autoridad pública, que priva a un particular de una cosa corporal (como una nave o la carga a transportarse en ella), por una causa de utilidad pública o una razón social. En nuestro ordenamiento jurídico, el artículo $19 \mathrm{~N}^{\circ} 24$, inciso $3^{\circ} \mathrm{CPol}$. dispone: "Nadie puede, en caso alguno, ser privado de su propiedad, del bien sobre que recae o de alguno de los atributos of facultades esenciales del dominio, sino en virtud de ley general o especial que autorice la expropiación por causa de utilidad pública o de interés nacional, calificada por el legislador".

Se trata de una orden del legislador, general o especial, de privación de la propiedad o su uso, que afecta a la nave o la carga a transportarse en ella, como también puede afectar al combustible ${ }^{12}$, contenedores, e incluso podría recaer sobre los fletes devengados o por devengarse con ocasión de uno o más viajes.

Desde el punto de vista substantivo, la diferencia entre la expropiación y el embargo es que éste es una restricción al uso de las cosas y a la actividad de los agentes de comercio, mientras que la expropiación es una privación de la propiedad o uno de sus atributos esenciales de una cosa utilizada en la aventura marítima. El embargo es una prohibición genérica, que se destina a todas o algunas cosas (mercancías, nave, combustible) o a otras actividades, como celebrar contratos de servicios (por ejemplo, bancarios, financieros, de seguros, de transporte, etc.), y está concebida en forma general y abstracta. Por su parte, la expropiación es específica, ya que se priva la propiedad, el uso u otro atributo de una cosa determinada o específica, que es el objeto de la expropiación.

Desde el punto de vista de la proyección o alcance de sus efectos, el embargo es internacional, al producir efectos respecto de situaciones que ocurren fuera del país que lo decreta, no así la expropiación que -por regla general- produce efectos dentro del país en que se expropia.

Desde el prisma de su finalidad, el propósito del embargo es retributivo, constituye una represalia o sanción, mientras que la expropiación se funda en una razón de utilidad pública o social.

En cuanto a sus similitudes, la expropiación sólo comparte con el embargo en que ambos constituyen órdenes de una autoridad, de un Estado, que afectan a la nave o a la carga, sea privando de su propiedad a su dueño, o restringiendo su uso, lo que a su turno impide a los interesados llevar a efecto la expedición marítima, o la convierte en imposible de continuar si la aventura marítima ya se inició y la nave y carga están en el agua con rumbo

${ }^{12} \mathrm{Si}$ es de propiedad de un tercero, como sucede por ejemplo, cuando un fletador por tiempo, o un operador o administrador, son quienes han suministrado el combustible. La regla general es que el combustible pertenezca al naviero que ha armado la expedición. 
a destino. Esta orden o acto imperativo de un tercero, ajeno a la expedición marítima, le sobreviene a ésta como un imprevisto al que es imposible resistir, y la convierte en imposible de realizar, pudiendo configurarse un caso fortuito o fuerza mayor. Como apunta Ruiz Soroa, "se trata de los supuestos de actos de coacción por parte del poder público que impiden el viaje"13. En Chile, el artículo $45 \mathrm{CC}$. coloca al acto de autoridad como uno de los ejemplos de caso fortuito o fuerza mayor, tema que trataremos en el siguiente acápite.

En el derecho inglés, en la teoría general de los contratos, la expropiación es uno de los casos de "frustration" del contrato ${ }^{14}$. "El cumplimiento de un contrato puede ser relevado, fundado en la frustración, cuando algo sucede con posterioridad a su celebración y lo transforma en física o comercialmente imposible de cumplir, o transforma la obligación que nace de él en un obligación que es radicalmente distinta a la que se contrajo al momento de celebrarlo"15.

\section{Embargo, requisición y confiscación.}

El término "requisar" es definido como "Dicho de la autoridad militar, en tiempo de guerra, o de la autoridad civil, en caso de calamidad pública: Expropiar, con efecto inmediato y sin seguir el procedimiento ordinario, cosas, derechos y servicios" 16 .

Por su parte, la palabra "confiscar" (del latín confiscāre) es conceptualizada por la Real Academia Española como "penar con privación de bienes, que son asumidos por el fisco", o "decomisar"17.

A la luz de la definición de la Real Academia, en ambos casos hay una privación de la propiedad o restricción a su uso, pero en la requisición se funda en una causa de utilidad pública (interna o externa), mientras que la confiscación importa una sanción criminal.

En nuestro entender, son figuras distintas y no necesariamente serán equivalentes. La requisición es la privación del uso de una cosa (como una nave, su combustible, contenedores o carga a bordo, la que se funda en una situación de emergencia, por causas ocurridas dentro o fuera del país, por ejemplo, guerra, conmoción, disturbios, desastres naturales, catástrofes, etc., y por lo mismo es transitoria, dura mientras subsista la emergencia que la explica y fundamenta.

${ }^{13}$ Ruiz Soroa, J. M., y otros, cit. (n. 4), p. 428.

${ }^{14}$ The Common Law Library, Chitty on Contracts (27a edición, London, Sweet \& Maxwell 1994), I, p. 1106.

${ }^{15}$ Ibíd., p. 1095.

${ }^{16}$ Diccionario de la Lengua Española en http://lema.rae.es/drae/, visitado el 10 de septiembre de 2014.

${ }^{17}$ Ibíd. 
Por su parte, la confiscación, es la privación de la propiedad de una cosa, de manera permanente, y a modo de castigo o sanción, como sucede con los instrumentos y efectos de un delito o infracción, cuando son decomisados.

En lo que se refiere a la confiscación y al comiso o decomiso, creemos que -al menos en Chile- no son lo mismo, puesto que el comiso es una pena criminal que aparece definida en el artículo $21 \mathrm{CP}$., como la "pérdida o comiso de los instrumentos o efectos del delito." Si bien comparte con la confiscación el rasgo en que ambas constituyen privaciones de la propiedad, el comiso es una sanción criminal, no así la confiscación.

A nivel de texto legal, ubicado en el título $7^{\circ}$ de la Ley de Navegación, titulado "De la reserva naval", los artículos 98 a 100 del Decreto-ley N 2.222 de 1978 (Ley de Navegación), disponen que: "en caso de emergencia nacionalo internacional, el Director, previo decreto del Presidente de la República, podrá tomar a su cargo la movilización de las naves mercantes y especiales, como también los servicios portuarios de todo el litoral [...]”, lo que implica que “[...] los capitanes y las dotaciones de todas las naves o artefactos navales [que] forman parte de la Reserva Naval de la República [...]" y que: "[...] se incorporarán al servicio activo en caso de guerra”. Desde el punto de vista de la dirección y control de dichas embarcaciones, ellas pasan a ser operadas por el Estado, a menos que los propietarios, armadores u operadores consientan en continuar por cuenta propia las operaciones comerciales.

También se refieren a la requisición los artículos 17 y 18 de la Ley $\mathrm{N}^{\circ}$ 18.415; Orgánica constitucional de los estados de excepción, que permite efectuar requisiciones de bienes o establecer limitaciones al ejercicio del derecho de propiedad.

En el derecho inglés, "requisition" o requisamiento por orden de la autoridad administrativa constituye un caso de "restraint of princess". "La requisición no es sino el arriendo de la nave, y su efecto es que Su Majestad tiene el poder para hacer que el dueño de esa nave celebre ese contrato de arrendamiento. El dueño de la nave no tiene la alternativa de aceptar o no la proposición de arrendamiento, pero la nave es, después de todo, una nave arrendada. No priva al dueño de su propiedad para conferírsela a Su Majestad y por tanto ese buque no está, para todos los efectos, en la misma posición que un buque de propiedad de la Corona"18.

Los casos de requisición son propios de los tiempos de guerra, especialmente de la Segunda Guerra Mundial, en que se requisaron naves mercantes para fines militares, razón por la que este se considera como un riesgo propio de la guerra, que se incorpora en las pólizas marítimas mediante la Cláusula

${ }^{18}$ The Broadmayne [1916] P64, CA, citado por Hodges, Susan, Cases and Materials on Marine Insurance Law (London, 1999), p. 590. 
adicional de guerra (Institute War Strike Clause $1 / 11795)^{19}$. Un buque puede ser requisado para propósitos específicos, sea por medio de un decreto o de manera informal, por un tiempo más o menos largo, por pocas horas o días ${ }^{20}$.

\section{Embargo, captura, apresamiento y otros riesgos de guerra.}

El apresamiento incluye cualquier acto de aprehender o tomar por un enemigo beligerante, mientras que captura es más amplia, por cuanto se extiende a comprender cualquier acto de posesión mediante el uso de la fuerza ${ }^{21}$, esto es, un acto de autoridad que conlleva el uso de la mano dura ("strong hand"), o un acto coercitivo.

Las palabras captura y apresamiento ("capture and seizure") van de la mano en el derecho inglés desde siglos, en las cláusulas de exclusión "Free of capture and seizure" (F.C. \& S., libre de captura y apresamiento) del Instituto de Aseguradores de Londres, así como en la Marine Insurance Act de 1906. Tras un fallo de la Cámara de los Lores que otorgó cobertura a las pólizas de seguro en eventos bélicos, el mercado asegurador de Londres reaccionó mediante la creación de la cláusula F.C. \& S., que excluía a los riesgos de captura, arresto, embargo, detención, restricción y sus consecuencias, transformándola en una cobertura excluida y excepcional, que se obtiene a través del adicional de riesgos de guerra, para casco marítimo y para transporte marítimo de carga ${ }^{22}$.

En el caso de la retención por orden de potencia extranjera, denominada detainment, estamos en la familia de los riesgos de guerra. Se asimila al requisamiento o requisición por orden de la autoridad administrativa, en que en ambos casos hay privación de la propiedad o del uso de una cosa, por efecto de un acto coercitivo ("strong hand") de una autoridad pública, pero en un caso la autoridad es nacional, y en otro es una autoridad foránea.

\section{Embargo y represalia.}

La represalia ("reprise") es un reactivo contra una lesión o afrenta recibida en un propio derecho, en que el lesionado puede, a su vez, lesionar el derecho del ofensor. "Esta lesión puede tener efecto sin que exista un estado de guerra, o durante la guerra, por una nación beligerante frente de otra beligerante o de sus aliadas". "El bloqueo pacífico y el embargo pueden constituir represalias, y por tanto riesgo de guerra, sin que éste sea declarado de hecho"23.

${ }^{19}$ Barroilhet, Claudio, Derecho del seguro maritimo (Santiago, Librotecnia, 2007), p. 173.

${ }^{20}$ O'May, Donald, On Marine Insurance (London, 1993), p. 273.

${ }^{21}$ Barroilhet, C., Derecho del seguro maritimo, cit. (n. 19), p. 170.

${ }^{22}$ Ibíd., p. 171.

${ }^{23}$ Ibíd., p. 175. 
En materia de seguro marítimo, la retención y la represalia son riesgos de guerra, pero en el derecho chileno, el artículo 1162 CCom., dispone: "La aventura y su extensión dependen de lo que las partes estipulen en el contrato de seguro. No obstante, a falta de estipulación en contrario, se entienden incluidos en el riesgo los peligros que provengan o que puedan ocurrir como consecuencia de la navegación o de estar la nave o artefacto naval en puerto o detenidos, incluyendo en este concepto los peligros derivados de las condiciones del tiempo, incendio, piratas, ladrones, asaltantes, capturas, naufragios, varamientos, abordajes, cambios forzados de ruta, apresamiento, saqueo, requisamiento por orden de la autoridad administrativa, retención por orden de potencia extranjera, represalia y, en general, todos los casos fortuitos que ocurran en el mar u otros medios [...]". Por lo que el ámbito de aplicación de la represalia excede a la guerra.

\section{Embargo y presas.}

El apresamiento consiste en la captura de una nave, y como tal es una situación de hecho, mientras que la declaración de presas es una resolución que declara o constata la procedencia y justificación del apresamiento, de acuerdo a las normas que lo regulan, que son normas propias de la guerra.

El apresamiento es una captura de buques efectuada durante la guerra. Es un modo propio del derecho internacional público, que está regulado en la Convención de las Naciones Unidas sobre derecho del mar del año 1982 y también existen normas que lo regulan en el Código Civil.

Esta captura se efectúa por un Estado beligerante, a través de sus buques de guerra, que apresan naves mercantes de pabellón enemigo, aunque excepcionalmente, pueden apresarse naves de Estados neutrales, por ejemplo, si no portan los documentos regulares, violan o intentan violar bloqueos, acarrean materiales de guerra o participan manifiestamente en acciones hostiles, etc.

Existe apresamiento cuando la captura o aprehensión material de la nave, es declarada judicialmente una presa, por un tribunal de presas, que declara que ha operado el apresamiento. Tras esta declaración, la nave está en condiciones de ser matriculada a nombre del Estado aprehensor ${ }^{24}$.

El artículo 640 CC. dispone: "El Estado se hace dueño de todas las propiedades que se toman en guerra de nación a nación, no sólo a los enemigos sino a los neutrales, $y$ aun a los aliados y los nacionales según los casos, y dispone de ellas en conformidad a las Ordenanzas de Marina y de Corso". Su artículo 641 preceptúa: "Las presas hechaspor bandidos, pirataso insurgentes, no transfieren dominio, y represadas deberán restituirse a los dueños, pagando éstos el premio

\footnotetext{
${ }^{24}$ Citas no textuales ibíd., p. 152.
} 
de salvamento a los represadores. / Este premio se regulará por el que en casos análogos se conceda a los apresadores en guerra de nación a nación."

La declaración de presas y el embargo comercial son actos de la autoridad, y ambas son coercitivos o imperativos, pero el embargo constituye una prohibición general que se aplica a todas las cosas o mercancías cubiertas por el decreto, mientras que la declaración de presas afecta específicamente a una nave y su carga a bordo.

Ahora, ambas comparten efectos, por cuanto la declaración de presas sí puede configurar un acto de la autoridad ("restraint of princess"), como sucede en el derecho inglées ${ }^{25}$.

\section{Embargo, saqueo, pirateria, ladrones y asaltantes.}

Saquear es "apoderarse de todo o la mayor parte de aquello que hay o se guarda en algún sitio"26. El saqueo puede tener su origen en un riesgo ordinario de la navegación, un acto de sublevación popular o de guerra, de hecho, una de las acepciones de su definición es "apoderarse violentamente los soldados de lo que hallan en un lugar" 27 .

Existen otras figuras que son similares al saqueo, cuyo denominador común es atentar contra la propiedad, como son la piratería, el robo, hurto, rateo y el faltante.

Piratas ("Piracy"). "Pirata es el ladrón del mar que ataca por la violencia mediante bandas organizadas al fin de rapiña" ${ }^{28}$. Su acción carece de motivación política, ya que sólo busca arrebatar cosas ajenas para sí, por lo que debe distinguírselo de quien actúa por los mismos medios, pero para otros fines $^{29}$. Los piratas son "gente que no reconoce bandera o país y que saquean, sin distinción, en su propio provecho personal" ${ }^{30}$. Pero "la noción de pillaje es más amplia que la de piratería, ella comprende la piratería" ${ }^{1}$. La sustracción de la materia asegurada con violencia se considera robo ("theft"), sin violencia o clandestina se considera hurto o ratería ("pillferage") y, tratándose de la carga, la desaparición de uno o más bultos se considera como faltante

${ }^{25}$ Boyd y otros, Scrutton on Charter Parties, cit. cit. (n. 2), p. 203.

${ }^{26}$ Real Academia Española, Diccionario de la Lengua Española (21 edición, Madrid 1996), p. 1846.

${ }^{27}$ Ibíd., p. 1846.

${ }^{28}$ BrunetTi, Antonio, Derecho marítimo privado italiano (Traducción de R. Gay de Montilla, Barcelona 1950), III, p. 462.

${ }^{29}$ Ibíd.

${ }^{30}$ Dover, citado por Simone, Osvaldo Blas, Seguros maritimos (Buenos Aires 2002), p. 140.

${ }^{31}$ De SMET, citado por Brunetti, cit. (n. 29), p. 463. 
o falta de entrega ("non delivery"). Si proviene de un accionar ilícito de la tripulación, se denomina baratería.

En la tarea de darle un alcance al término piratería, para efectos del riesgo asegurado en unas póliza marítima, la jurisprudencia inglesa ha incluido a los desordenes desde la costa y a los pasajeros amotinados ${ }^{32}$. La nota distintiva de la piratería es que se requiere del uso de la violencia, sin que tenga una motivación política, sino que el uso indiscriminado de la fuerza por un afán personal. Se lo considera un riesgo marítimo, a diferencia de los asaltantes y ladrones, que cae dentro de la cobertura de guerra.

"El significado del término 'rover' estaba cercano y afín al de pirata; es una expresión antigua que aludía a los remeros independientes quienes vagabundeaban ('roamed o roved') los mares en la esperanza de encontrar mercaderes cargados de bienes valiosos a quienes pudieran abordar y robar" 33 .

El término "asaltantes" ("thieves") se ha interpretado como inclusivo "el robo de cualquiera especie, sino que sólo el robo de ladrones asaltantes ("assailting thieves"), esto es, robo con violencia, aunque no necesariamente en contra de determinada persona" ${ }^{34}$.

\section{Embargo y huelga, motines, disturbios, tumultos y revueltas.}

$\mathrm{Al}$ igual que la guerra, las huelgas y los motines, disturbios, tumultos y revueltas no son peligros del mar ("perils of the sea") o riesgos propiamente marítimos, aunque sobrevengan en el curso de la navegación y del comercio marítimo.

Motín es un "movimiento desordenado de una muchedumbre, por lo común contra la autoridad constituida" ${ }^{35}$.

Disturbio es una "alteración, turbación de la paz y concordia"36.

Tumulto es sinónimo de "motín, confusión, alboroto producido por una multitud", y de "confusión agitada o desorden ruidoso" 37.

Revuelta significa “alboroto, alteración, sedición, riña, pendencia, disensión”, entre otras acepciones ${ }^{38}$.

El Diccionario de la Lengua Española define la huelga como "interrupción colectiva del trabajo con el fin de imponer ciertas condiciones o manifestar

${ }^{32}$ Hodges, Susan, Cases, cit. (n. 18), p. 415.

${ }^{33}$ Barroilhet, C., cit. (n. 19), p. 162.

${ }^{34}$ Ibíd., p. 162.

${ }^{35}$ Diccionario de la Lengua Española, cit. (n. 16), visitado el 13 de septiembre de 2014.

${ }^{36}$ Ibíd.

${ }^{37}$ Ibíd.

${ }^{38}$ Ibíd. 
una protesta" 39 . En sí, se trata de un movimiento laboral que importa una suspensión de la actividad laboral, por parte de los trabajadores o funcionarios que buscan mejoras salariales o cambios en las condiciones del trabajo, interrupción de labores a la que pueden agregarse otros riesgos anexos, que importan otras situaciones que pueden ser análogas en cuanto a sus efectos, como los desórdenes, tumultos, revueltas, motines, saqueos, tomas, etc.

En materia marítima y portuaria, es usual que a la huelga sucedan tomas, bloqueos, obstrucciones y otras interrupciones de las actividades, operaciones y maniobras que se llevan a efecto en los puertos y terminales de carga y descarga, precisamente, para asegurar el cumplimiento de la huelga y garantizar su éxito.

Entonces, una huelga de trabajadores portuarios, estibadores, operadores, funcionarios (públicos o privados) que se relacionen al movimiento, depósito, carguío, estiba o manipulación de las cargas, o de las actividades marítimas y ribereñas, pueden conllevar bloqueos, disturbios y revueltas, que configuren otros eventos de casos fortuitos o fuerza mayor.

\section{Colofón.}

Como puede apreciarse, junto al embargo, interdicción o prohibición de comerciar, existe una serie de figuras que son conceptualmente distintas, pero que pueden generar los mismos efectos, sea por la vía del caso fortuito, fuerza mayor, "restraint of princess" o "frustration".

Para efectos de este artículo, la palabra embargo sin otra calificación, se entiende comprender al embargo comercial, interdicción o prohibición de comerciar, ya definida y delimitada.

\section{EMBARGo y CASO FORTUITO (“FORCE MAJEURE”)}

$\mathrm{El}$ artículo $45 \mathrm{CC}$. define al caso fortuito o fuerza mayor (expresiones que considera sinónimas) como "el imprevisto a que no es posible resistir". El mismo precepto coloca ciertos ejemplos de caso fortuito, uno de los cuales son los denominados actos de autoridad, categoría dentro de la cual se incluyen los embargos internacionales, que son interdicciones o prohibiciones de comerciar decretadas por la autoridad.

Según Abeliuk, los elementos que configuran la noción son: i) la existencia de un hecho extraño a la voluntad de las partes; que sea ii) imprevisible; y iii) insuperable.

El hecho debe ser “ajeno a la voluntad e intervención de las partes”, debe

${ }^{39}$ Ibíd., p. 1128.

${ }^{40}$ Abeliuk Manasevich, René, Las obligaciones (3ª edición, Santiago, Editorial Jurídica de Chile, 1993), II, p. 688. 
ser tal "que las partes no lo han podido prever al celebrarse el acto o contrato ni el deudor al momento de presentarse" ${ }^{41}$ y debe ser imposible de resistir, lo que ocurre "cuando no es posible evitar sus consecuencias, en términos que ni el agente ni ninguna otra persona colocada en sus mismas circunstancias habría podido hacerlo" ${ }^{42}$.

En términos generales, sin adentrarnos aún en la configuración interna de alguna de las instituciones del derecho de la navegación que trataremos más adelante, a continuación analizaremos la concurrencia de los elementos del caso fortuito en la figura del embargo o prohibición de comerciar.

\section{Primer requisito: externalidad.}

El primero consiste en la existencia de un hecho extraño a la voluntad de las partes, vale decir, que se haya originado sin participación de las partes involucradas en la relación jurídica de que se trate.

Tal como lo explicamos al analizar la definición de embargo, se trata de una prohibición de comerciar que se decreta por una autoridad (sea nacional, internacional o supranacional), porque sólo ésta cuenta con una mano fuerte o dura ("strong hand") para imponerla.

Si la prohibición proviene de personas que no sean un Estado, gobierno (aún de facto) o de quienes detentan el poder ("rulers"), podríamos estar en presencia de un bloqueo, o de un boicot, si se trata de una decisión colectiva de varias personas de abstenerse de comerciar con determinadas zonas, Estados o productos. También podría ser fruto de un motín, revuelta o disturbio, dentro del contexto de una protesta o de una huelga.

\section{Segundo requisito: imprevisibilidad.}

El segundo requisito, que consiste en que el evento sea imprevisible, es la bisagra que gira y permite determinar la concurrencia o no concurrencia de la fuerza mayor en la especie.

Para resolver acerca de su aplicación, es necesario determinar el momento, o al menos el espacio de tiempo, dentro del cual ha de evaluarse si el embargo era o no previsible. En general (sin entrar al detalle interno de cada una de las figuras o instituciones a través de las cuales se presenta el embargo, como "restrint of princess", "frustration" o "force majeure") podemos plantear que existe un rango de tiempo dentro del cual oscila el momento exacto en que se debe determinar si el embargo era o no previsible, y este margen va desde que se celebra el contrato (en materia marítima, contratos de fletamento, transporte marítimo o seguro marítimo) y hasta el inicio de la aventura

\footnotetext{
${ }^{41}$ Ibíd.

${ }^{42}$ Ibíd., p. 689.
} 
marítima. Dicho a la inversa, si el embargo existía antes de la celebración del respectivo contrato, pudo haber sido previsible por las partes contratantes al consentir en su celebración (y no concurriría este requisito en la especie), mientras que si sobreviene con posterioridad al inicio del viaje o comienzo de la aventura marítima, está llamado a constituir una circunstancia que no era previsible al momento del zarpe.

\section{Tercer requisito: insuperabilidad.}

El tercer requisito, que el hecho sea insuperable, suele confluir por la propia definición del embargo, que consiste en una prohibición de la autoridad de comerciar, esto es una orden de la autoridad, que además se manifiesta de manera coercitiva ("strong hand") e imperativa, al conllevar drásticas sanciones por su incumplimiento, tales como multas, e incluso penas privativas de libertad por desacato de la orden de la autoridad. Así por ejemplo, en el caso del embargo de los Estados Unidos de Norteamérica hacia Irán (al que nos referimos en el acápite siguiente), se establecen multas por hasta US\$1.000.000, y prisión de hasta 20 años, para los delitos que importen su violación, así como multas de hasta US\$250.000, en caso de infracciones administrativas.

Entonces, el embargo o prohibición de comerciar, podría configurar un caso fortuito en la legislación nacional, en la medida que reúna los requisitos antes analizados.

El principal efecto del caso fortuito es que exime de responsabilidad, al transformar el incumplimiento de las obligaciones en inimputable, según lo preceptúa el inciso segundo del artículo 1547 CC., que dispone: "El deudor no es responsable del caso fortuito, a menos que se haya constituido en mora (siendo el caso fortuito de aquellos que no hubieran dañado a la cosa debida, si hubiese sido entregada al acreedor), o que el caso fortuito haya sobrevenido por su culpa. / La prueba de la diligencia o cuidado incumbe al que ha debido emplearlo; la prueba del caso fortuito al que lo alega".

El caso fortuito es una institución que también es frecuente en el derecho comparado. "La expresión cláusulas de "force majeure" se usa normalmente para describir un término contractual por el cual una (o ambas) de las partes se eximen del cumplimiento del contrato, en todo o en parte, o está habilitada para suspender su ejecución o para solicitar una extensión del plazo para cumplir, sobre la ocurrencia de un evento o eventos específicos más allá de su control" ${ }^{3}$. En el derecho inglés, "force majeure" tiene su fuente en la convención, y debe pactarse por medio de cláusulas que sean explícitas y contengan situaciones que la configuran, puesto que se trata de una excep-

\footnotetext{
${ }^{43}$ Chitty on Contracts, cit. (n. 14), p. 704.
} 
ción al cumplimiento de lo pactado, de manera que no se les reconoce a las cláusulas genéricas ese efecto liberatorio. Sus elementos son similares a los establecidos en la legislación chilena ${ }^{44}$.

En el "common law", en general el embargo configura un evento de force majeure, al enmarcarse dentro del concepto de "act of King" ("acto del gobernante"), "restraint of princess, rulers or people" ("restricciones del gobernante o de la gente"), que son situaciones que se consideran per se como "force majeure".

Pero hay que ser cuidadoso con la concurrencia, en la especie concreta o materia que se trate, de los elementos de la figura, y en especial el de la previsibilidad, que debe analizarse cuidadosamente caso a caso. En otras palabras, un embargo no configura un caso fortuito de manera automática e irrefutable, porque es posible que la prohibición de comerciar haya sido previsible al momento de celebrar el contrato, o del inicio de la aventura marítima. Se trata entonces de un asunto esencialmente casuístico.

\section{OBJETO DEL EMBARGo}

La prohibición de comerciar recae sobre cosas corporales, mercancías u objetos, categoría que es amplia y puede incluir las siguientes cosas que se relacionan a la actividad marítima: mercancía, nave y fletes. También puede incluir servicios o actividades:

i) Mercancía o carga: Un embargo puede afectar a todo tipo de cosas, bien sean cosas singulares o cuerpos ciertos, o cosas genéricas, como los líquidos y sólidos a granel. Veamos algunos ejemplos: Armas, materiales, insumos y elementos para fabricarlas, operarlas y mantenerlas, municiones y pertrechos; Petróleo, crudo y otros derivados; Cañerías, materiales, insumos y elementos para la industria petrolera (extracción, refinación, distribución, etc.); Vegetales y productos agrícolas; Animales; Alimentos procesados; Medicamentos, aunque estos y los artículos hospitalarios, de medicina y de ayuda humanitaria, se excluyen de las resoluciones de prohibición.

ii) Nave y otros medios de transporte. Generalmente, las interdicciones de comerciar afectan a las mercancías y productos, pero las naves y demás medios de transporte pueden verse retenidos, arrestados o arraigados por portar mercancías prohibidas, o si estamos frente a una figura delictiva, puede estimarse que el medio de transporte fue un instrumento utilizado para la comisión del delito y, por ende, queda sujeto a comiso o decomiso, que es una pena privativa de su propiedad, a consecuencia de su uso delictivo.

iii) El flete. El flete, esto es, el precio o estipendio que se paga por fletar

${ }^{44}$ Ibíd., p. 710. 
o arrendar una nave en el contrato de fletamento (que se denomina "hire"), o el precio que se paga por el transporte de mercancías por mar a virtud de un contrato de transporte marítimo (que se conoce como "freight") también pueden ser objeto de un embargo, se trata de derechos personales o de crédito, que son una especie de los derechos incorporales. Lo mismo, sucede con el pasaje, que es el precio del transporte de un pasajero y su equipaje, en un contrato de pasaje.

Tratándose de cosas incorporales, también pueden afectarse por una prohibición y embargo otros derechos personales, como las primas o indemnizaciones de seguros, las cartas de crédito y los créditos documentarios, las remesas internacionales, los préstamos y otros.

Un buen ejemplo de los objetos y actividades que pueden afectar a un embargo es el documento "An overview of O.F.A.C. Regulations involving Sanctions against Iran" 45 "Una visión panorámica de las regulaciones que contienen sanciones a Irán"), que contiene información general de las sanciones impuestas a Irán en las "Iranian Transactions Regulations", 31 C.F.R. Parte 560 ("Regulaciones de transacciones iraní"), e "Iranian Assets Control Regulations", 31 C.F.R. Parte 535 ("Regulaciones de control de bienes iraníes"), que son administradas por el U.S. Treasury Department's Office of Foreign Assets Control ("Oficina del Ministerio de Hacienda para el control de los bienes en el extranjero"). Este embargo incluye: $i$ ) Importaciones de bienes desde Irán y exportaciones hacia Irán, directa o indirectamente, a través de terceros países, o bienes para su uso o empleo sustantivo por el gobierno iraní, así como las donaciones para ese mismo fin; ii) Ventas y demás transacciones de estos bienes, incluyendo la compra, venta, transporte, aseguramiento, "swap", financiamiento, agenciamiento o corretaje de bienes y servicios de origen Iraní o que pertenezcan o sean controlados por su gobierno; iii) Traspaso o suministro de tecnología, información, término que es amplio y contiene las publicaciones, películas, afiches, grabaciones de audios, microfilms, discos compactos, CD ROMs, revistas y producciones artísticas; $i v$ ) Inversiones, con incvlusión de aportes de fondos, bienes, capital, préstamos, créditos, en la propiedad iraní o en las entidades de propiedad o control de su gobierno; $v$ ) Se prohíbe a las entidades financieras de los EE. UU. procesar transferencias, dolarizar transacciones, a través del sistema financiero norteamericano, para uso o beneficio directo o indirecto de bancos iraníes o del gobierno de Irán. Es importante señalar que varios bancos iraníes han sido designados como "Specially Designated Global Terrorist"

${ }^{45}$ Emitido por el Office of Foreign Assets Control, U.S.A., Department of the Treasury, que se ve enb: http://www.treas.gov/ofac, consultada el 13 de septiembre de 2014. 
(“Terrorista global especialmente designado"); vi) Se prohíbe la comercialización de productos o servicios relacionados a la industria del petróleo iraní, o su financiamiento, información, tecnología o cooperación con ellas; vii) Se prohíbe financiar las transacciones proscritas por el embargo, dentro o fuera del sistema bancario; viii) Se excluyen del embargo los artículos de ayuda humanitaria como alimentos, ropas, medicinas, remedios, productos agrícolas, artículos médicos y otros; ix) Otros pagos, servicios o actividades.

Las prohibiciones de comerciar pueden extenderse a determinadas actividades o servicios, como los servicios a la industria portuaria, marítima, los seguros, las transferencias bancarias, servicios de telecomunicaciones, los vuelos sobre el espacio soberano, los transbordos marítimos o aéreos, las inversiones, adquisiciones de inmuebles u otras propiedades, etc.

\section{EMBARgo EN EL FLETAMENTO DE NAVES}

El fletamento es un contrato en cuya virtud, una parte denominada fletante, pone el uso de una nave a disposición de otra parte denominada fletador, para que éste la emplee, a cambio del pago de un flete.

En el derecho chileno, existen tres clases de fletamentos típicos: a casco desnudo, por tiempo y por viaje. En los dos primeros tipos, el fletante coloca la nave a disposición del fletador por un tiempo determinado, con la diferencia que en el fletamento a casco desnudo existe entrega de la nave al fletador, a quien el fletante traspasa su tenencia, control y explotación (incluyendo el derecho a designar al capitán y a la tripulación), no así en el fletamento por tiempo, en que el fletante, conservando su tenencia y control, pone a disposición del fletador el empleo y explotación de la nave, dentro de los términos del contrato.

Por su parte, en el fletamento por viaje, el fletante pone a disposición del fletador el uso de uno, varios o todos los espacios de carga de la nave, para que éste los utilice en uno o más viajes determinados.

¿Cuáles son los efectos del embargo internacional en los fletamentos?

La respuesta pasa por distinguir la clase de fletamento de que se trate.

$1^{\circ}$ En los fletamentos a casco desnudo y por tiempo, una prohibición de comerciar que afecte a la mercancías o carga que se intenta transportar en la nave objeto del contrato, no configura en principio un caso fortuito o fuerza mayor, que libere al fletador de sus obligaciones contractuales (como las de emplear adecuadamente la nave, pagar el flete al fletante, restituir la nave al término del contrato, etc.) ni habilita al fletador a solicitar el término del contrato.

La ratio legis estriba en que en estos contratos, tras el embargo internacional, el fletador bien podría transportar otro tipo de mercancía o carga 
que aquella que está prohibida hacia un destino determinado, y/o podría transportarla hacia otros destinos, de manera que aún es posible un uso alternativo de la embarcación. La carga y destino en que el fletador desee emplear la embarcación al contratar la nave, constituyen su causa ocasional de la celebración del contrato, esto es, el motivo personal que busca al contratar su uso, pero no integran un elemento propio del contrato, de manera que la prohibición sobreviniente de transportar ese tipo de carga y al destino pretendido por el fletador, sólo integran su alea contractual, y no generan efecto en los derechos y obligaciones del fletador.

Dicho de otra forma, si después de celebrado el fletamento, sobreviene una prohibición de comerciar con la mercancía y a los destinos en que el fletador pretendía usar la nave, esto en principio no empece al fletante, y consecuentemente, no libera al fletador de sus obligaciones, ni le habilita a terminar el contrato. Decimos en principio, dado que las partes contratantes pueden alterar estas normas, mediante la inclusión de cláusulas contractuales que, de manera expresa o implícita, permitan arribar a una conclusión que sea distinta.

$2^{\circ}$ De otra parte, no sucede lo mismo en el fletamento por viaje, porque ciertos artículos del Codigo de Comercio regulan expresamente la situación de una prohibición de comerciar las mercancías a embarcar en la nave fletada. Estas normas son el artículo 961: "El contrato quedará resuelto sin derecho a indemnización de perjuicios para ninguna de las partes, si antes del zarpe de la nave sobreviene una probibición para comerciar con algún pais al cual ib a destinada, o si acaece cualquier otro suceso de fuerza mayor o caso fortuito que haga imposible la realización del viaje"; y el artículo 962: "Cuando el caso fortuito o la fuerza mayor sobrevinientes fueren de carácter temporal $y$ significaren sólo un retardo en el zarpe, la ejecución del contrato se entenderá suspendida por todo el tiempo que dure el impedimento. / De igual manera, el contrato no se resuelve y mantiene plena vigencia, si el caso fortuito o la fuerza mayor ocurren durante el viaje. Cuando asi suceda, no habrá lugar a aumento del flete y el fletante deberá continuar el viaje tan pronto como cese el impedimento. / Cuando se trate de impedimento temporal, el fletadorpodrá descargar las mercancias a su costa en el lugar que señale, debiendo pagar al fletante un flete proporcional a la distancia recorrida."

La solución de estas normas supone una doble distinción: el momento en que sobreviene el embargo y la duración del mismo. De la combinación de ambos criterios fluyen las soluciones legales:

a) Si el embargo es anterior al zarpe de la nave, o al comienzo del viaje. El artículo 961 contempla el caso fortuito y, en especial, la prohibición de comerciar con el país de destino, y si aquélla constituye un 
impedimento total de su realización, el contrato quedará resuelto sin derecho a indemnización.

Esta figura se caracteriza así: i) Debe tratarse de una imposibilidad absoluta del viaje, esto es, ni siquiera más largo u oneroso, sino que debe consistir en un impedimento total; $i$ ) Opera sin que sea necesario que se alegue por las partes, porque no se contempla como una acción resolutoria para alguna de ellas; iii) Las partes contratantes no están obligadas a indemnizarse la una a la otra; iv) La figura coincide con la denominada "frustration" del fletamento en el derecho inglés.

Un fletamento se frustra cuando "producto de un evento extraño, fuera del control de las partes, se hace imposible conseguir el propósito comercial de la aventura a la que el fletamento sirve" ${ }^{16}$. Esto sucede cuando, a consecuencia de un obstáculo fáctico o de un impedimento legal, la realización del viaje se torna completamente imposible, lo que transforma al fletamento en un contrato completamente distinto al celebrado.

Ahora, si el impedimento es temporal, y sólo importa un retardo en el zarpe, el artículo 962 , inciso $1^{\circ} \mathrm{CCom}$. dispone que la ejecución del contrato se suspenderá por todo el tempo que dure el impedimento. La suspensión importa que cesan temporalmente las obligaciones de las partes, sin que ellas se consideren incumplirlas o retardar su cumplimiento, y por ende, sin que proceda indemnización de perjuicios alguna entre ellas, reanudándose el contrato, tan pronto como cese el impedimento.

b) Si el embargo es posterior al zarpe de la nave, o al comienzo del viaje. Esta situación se regula en el inciso $2^{\circ}$ del artículo 962 CCom., que dispone lo siguiente: "De igual manera, el contrato no se resuelve y mantiene plena vigencia si el caso fortuito o la fuerza mayor ocurren durante el viaje. Cuando asi suceda, no habrá lugar a aumento del flete y el fletante deberá continuar el viaje tan pronto como cese el impedimento."

La expresión "de igual manera" se entiende referida a que el impedimento es temporal (tal como sucede en el inciso primero), caso en que el contrato no se resuelve, sino que continúa vigente, y el impedimento sólo acarrea la postergación de la prosecución del viaje, pero no conlleva la terminación del contrato.

El único efecto distinto a la suspensión que contempla la norma es que se permite al fletador a descargar la nave, facultad establecida en el inciso final de la norma, que reza: "Cuando se trate de impedimento temporal, el fletador podrá descargar las mercancias a su costa en el lugar que señale, debiendopagar

${ }^{46}$ Cooke, Julian - Kimball, John - Young, Timothy - Martowsky, David Taylor, Andrew - Lambert, Le Roy, Voyage Charters (London, Lloyd's of London Press, 1993), p. 465. 
alfletante un flete proporcional a la distancia recorrida". Es lo que se denomina flete pro rata itineris.

$3^{\circ}$ Embargo en el transporte terrestre. La solución legal del artículo 961 CCom. se asimila a la del transporte terrestre. En efecto, el artículo 170 CCom., localizado en el párrafo $1^{\circ}$ sobre definiciones y generalidades del transporte por tierra, ríos, lagos y canales navegables, dispone: "Es también rescindible departe de ambos contratantes por la superveniencia de un suceso que impida emprender el viaje, como pérdida de los efectos, declaración de guerra, prohibición de comerciar, interceptación de caminos por tropas enemigas u otros acontecimientos análogos. I En cualquiera de estos casos la rescisión se verifica sin indemnización, y cada una de las partes sufre las pérdidas de sus aprestos y los perjuicios que le cause la rescisión".

Esta norma está estrechamente ligada al artículo 169 CCom., que establece: "El transporte es rescindible, a voluntad del cargador, antes o después de comenzado el viaje./En el primer caso, el cargador pagará al porteador la mitad, y en el segundo la totalidad del porte estipulado".

Pese al empleo del vocablo "rescindir", ambas normas establecen situaciones de resciliación unilateral, vale decir, "que una obligación o un conjunto de obligaciones contractuales pueden extinguirse por la voluntad de uno solo de los contratantes" ${ }^{\prime 4}$. No se trata de nulidad relativa, ya que en esta hipótesis no existe vicio.

En el caso del artículo 169, el contrato expira "por exclusiva voluntad del cargador, antes o después de comenzado el viaje"48. Otro autor añade: "Este derecho excepcional se otorga al cargador para quien el transporte es muchas veces un acto accesorio a su comercio principal" ${ }^{\prime \prime}$. Pero, a efectos de compensar al transportador de los perjuicios que esta terminación unilateral le irroga, se le impone al cargador el deber de pagar el "falso porte", ascendente a la mitad del porte, si lo rescilia antes del inicio del viaje, o de la totalidad, si lo hace comenzado que sea éste.

Pero la resciliación del artículo 170 CCom. es distinta en cuanto a su procedencia, oportunidad y efectos:

i) En primer lugar, desde el punto de vista de la procedencia, no se trata de un derecho absoluto del cargador, ni del porteador, de terminar el contrato sin expresión de causa, sino que de una resciliación unilateral fundada en un "suceso que impida emprender el viaje". Que sea un suceso significa que debe haber un acontecimiento, un hecho o una situación, que es externa a

${ }^{47}$ López Santa María, Jorge, De los contratos. Parte general (2a edición, Santiago, Editorial Jurídica de Chile, 1998), p. 322.

${ }^{48}$ Ibíd., p. 323.

${ }^{49}$ Eyzaguirre Echeverría, Rafael, Contrato de transporte y nociones de derecho maritimo y aéreo (Santiago, Editorial Jurídica de Chile, 1980), p. 28. 
la mera voluntad o deseo de una de las partes de no prosperar en el contrato. La ley coloca algunos ejemplos, como la pérdida de los efectos, declaración de guerra, prohibición de comerciar y la interceptación de caminos por tropas enemigas, que no son taxativos, ya que agrega "u otros acontecimientos análogos". Estas situaciones, si bien se parecen a eventos de caso fortuito o fuerza mayor, tampoco se limitan a ellas, ya que la pérdida de los efectos no necesariamente se circunscribe a una fuerza mayor.

ii) Pero no basta la ocurrencia de un suceso, sino que este debe ser determinante e incidente en la ejecución del contrato, al punto tal, que debe impedir su inicio. El Diccionario de la Lengua Española define impedir como "Estorbar, imposibilitar la ejecución de algo" ${ }^{\circ}$,

iii) En relación a la oportunidad, ella debe ejecutarse antes de que el viaje comience, la ley utiliza la expresión "emprender". En consecuencia, esta resciliación unilateral no produce efectos en forma retroactiva (como la nulidad), sino que opera ultractivamente. Tratándose de un contrato en que se pacten dos o más viajes sucesivos, se entiende que esta facultad se refiere y opera antes del inicio de cada uno de dichos viajes.

iv) El efecto es la terminación del contrato, que opera hacia el futuro, sin derecho a indemnización de perjuicios para los contratantes.

v) Cada parte sufrirá las pérdidas (o daños, a fortiori) de sus bienes, así como los gastos y demás perjuicios que cause la terminación, amén de los que sean consecuencia del evento que la explica y causa.

vi) Puesto que el viaje no se ha iniciado, no se produce el problema de dilucidar qué ocurre con la carga que se transporta, quien se encarga de retornarla a origen o de conducirla a destino, o quien lo paga. Simplemente, no habrá transporte después de la terminación, ni pago de su precio. Esto, a diferencia del artículo 169 en que sí hay pago, pese a que no hay transporte. Otra diferencia con el artículo 169 , es que esta facultad puede ejercerla tanto el cargador como el transportador.

La diferencia entre la solución del artículo 170 con la del artículo 961 es que (aparte de utilizar correctamente la expresión resolver en lugar de rescindir), este precepto se refiere exclusivamente al caso de imposibilidad para realizar el viaje y pone término al contrato de manera automática, ipso iure, a diferencia del artículo 170 que concede a las partes el derecho a resolverlo.

Otra diferencia es que el artículo 961 hace mención explícita al caso fortuito o fuerza mayor, lo que no sucede en el artículo 170, lo que permite reforzar la afirmación de que los eventos que configuran éste precepto (artículo 170) no se circunscriben a situaciones de fuerza mayor o caso fortuito,

${ }^{50}$ Diccionario de la Lengua Española, cit. (n. 16). 
y cabrían situaciones que imposibilitan la ejecución del transporte, aunque no cumplan con los requisitos de la fuerza mayor.

Entonces, si bien existe una similitud con la fuerza mayor, la institución del artículo 170 es una figura de tipificación especial, que opera de manera independiente, cuando se cumplen los supuestos del precepto, sin que sea necesario que concurran los elementos de la fuerza mayor como la imprevisibilidad y la irresistibilidad. Estas diferencias tienen su justificación en la particularidad que el contrato de transporte es, desde el punto de vista logístico y económico, un instrumento para la movilización de las cosas o las personas que, a su vez, constituye un medio para cumplir con otros negocios o contratos que integran la cadena de producción de bienes y servicios.

\section{EMBARGO EN EL TRANSPORTE DE MERCANCÍAS POR MAR}

1. La prohibición de comerciar una determinada mercancía afecta directa y consecuencialmente a su transporte marítimo, cualquiera sea el título o negocio que antecede y explica este transporte, por ejemplo, puede tratarse de la entrega de la mercancía exportada o vendida a virtud de una compraventa internacional de mercancías, o de otro negocio (comodato, arrendamiento, leasing, depósito, administración, etc.), o bien, ser mercancías propias del dueño o armador del buque, su operador o del transportador, quien las acarrea a bordo.

Al prohibirse la internación o tránsito de una mercancía hacia o un país o zona, por medio de un embargo, directamente se afecta su transporte hacia esa zona, su carga o descarga en puertos ubicados en ella, e incluso existen sanciones en las que se proscribe directa y señaladamente el transporte de las mercancías hacia las zonas interdictas.

2. ¿Qué sucede cuando las mercancías objeto de un transporte marítimo son objeto de una prohibición de comercio? La respuesta general es que se afecta e impide su acarreo, y por ende el desarrollo normal del contrato de transporte, pero la situación concreta en que ellas quedan, dependerá del momento en que se dicta la prohibición y de su objeto concreto.

Algunas prohibiciones posibles son éstas: de comerciar (genéricamente) con un país o zona; de importar determinadas materias primas y productos manufacturados a un país, o exportarlos desde el mismo; de transportarlas hacia o desde un país o zona; para las naves de recalar en determinados puertos o zonas; para naves de determinada nacionalidad de recalar en tales zonas; para los nacionales de un Estado de efectuar comercio, o prestar servicios de transporte marítimo, hacia un Estado zona afectada. 
Estas situaciones son similares, pero no idénticas, y los matices que las diferencian pueden repercutir en las soluciones que les sean aplicables.

Así, si se trata de una prohibición genérica de comerciar con un determinado país o zona, o específicamente respecto de determinadas mercancías, ellas no podrán transportarse hacia o desde los puertos que estén ubicados en aquellos. Si esta prohibición está concebida en términos territoriales, vale decir, se prohíbe el comercio (genérico o específico) entre determinados territorios, el transporte será legalmente imposible de efectuarse en ellos. Dependiendo como se redacte la prohibición, ella podría no afectar a un transporte que se efectúe desde o a través de otra zona o Estado hacia los destinos proscritos, de manera que podría pensarse en que si la mercancía se traslada hacia un país o zona no cubierta por el embargo, y desde ahí se lleva hacia su destino final, sería legalmente factible ejecutarla, pero en esta hipótesis hay que tener presente que esto podría constituir otro transporte distinto al traslado directo entre los dos lugares afectados por el embargo. Así por ejemplo, si se prohíbe el comercio de cobre desde Chile hacia Irán, podría estimarse que si el cobre se transporta desde Chile hacia un tercer Estado, y desde ahí a Irán, no se vulneraría el embargo, pero este transporte vía un tercer Estado puede constituir una prestación distinta al transporte directo y, por lo mismo, estaríamos en presencia de un cambio en la prestación vertebral que compone el objeto del contrato, alteración esencial que requiere aceptación de ambas partes contratantes.

3. Otro punto - de mayor importancia aún- es la situación que podría producirse tras una operación de triangulación en la cual las mercancías se internan, o se hacen ingresar en tránsito a un tercer país (al que no se le aplica el embargo), para desde ahí re-exportarlas o embarcarlas hacia su destino final. Esta hipótesis podría estar fuera del alcance del embargo, pero hay que ser cuidadoso, porque también podría configurarse una elusión del embargo, mediante una simulación de una venta o importación desde un tercer país no afectado por el embargo, tiñendo de ilegal al paso por el tercer país.

Tratándose de prohibición para las naves de recalar en determinados puertos o zonas, aquí también hay que distinguir si se trata de una prohibición decretada por el Estado a cuya bandera pertenece la embarcación, o de la persona del embarcador o transportador, en contraposición al decretado por un tercer Estado, ya que en la primera situación, la prohibición afecta precisamente a las partes del transporte, no así en la segunda hipótesis, en que nos enfrentamos ante un problema de alcance del efecto vinculante de la ley o la resolución que decretó el embargo.

Ejemplos: i) Si en un Estado A se prohíbe la exportación de mercancías desde ese Estado hacia un Estado B, sin mayor especificación, es posible que 
las mercancías puedan exportarse hacia un Estado C (en que el embargo no rija) y desde éste re-enviarse al Estado $B$, sin violar directamente el embargo en el Estado A; ii) Pero si en el Estado A se prohíbe el comercio con el Estado B, y esta prohibición afecta a los nacionales del Estado A, sus bienes (incluyendo las naves que enarbolan su bandera y las mercancías que proceden de él) y al territorio de ese mismo Estado (lo que comprende sus puertos), es poco probable que la operación pueda llevarse a efecto legalmente desde un tercer Estado, por nacionales o naves del Estado A; iii) Si la prohibición emana de un Estado C, y se aplica a embarques desde el Estado A hacia el Estado B, estaríamos en presencia de una aplicación extraterritorial de la resolución que decreta la prohibición, puesto que en principio, cada Estado, sólo puede dictar órdenes que se apliquen a su territorio, a sus nacionales y a sus bienes, que son los confines de su soberanía, y no puede regular operaciones que sucedan fuera del alcance de su propia ley, o de quienes esta vincula.

4. ¿Cómo afecta el embargo al contrato de transporte?

Afecta su médula: la obligación del porteador de acarrear mercancías, por mar, entre dos puertos, sea porque se prohíba la venta de mercancías (y consecuencialmente se proscribe su transporte, que es la forma de cumplir con la entrega que dimana de su venta), o bien, sea porque se prohíbe derecha y precisamente el transporte de la mercancía, como sucede en la gran mayoría de las prohibiciones actuales, que no sólo proscriben el comercio, sino que también el transporte de la carga afectada.

Para analizar el efecto concreto del embargo, hay que distinguir si éste rige desde antes de la celebración del contrato, o le sobreviene.

a) Embargo previo al contrato de transporte. En la primera hipótesis, si la mercancía objeto del transporte no puede comerciarse o transportarse hacia el puerto de destino, estamos ante un negocio prohibido por las leyes, y el contrato que recaiga sobre él, adolecerá de objeto ilícito, por así disponerlo el artículo 1466 CC.: "Hay asimismo objeto ilícito en las deudas contraídas en juego de azar, en la venta de libros cuy a circulación es probibida por autoridad competente, de láminas, pinturas y estatuas obscenas, y de impresos condenados como abusivos de la libertad de la prensa; y generalmente en todo contrato probibido por las leyes". También se aplica el artículo 10 CC., que dispone: "Los actos que probibe la ley son nulos y de ningún valor; salvo en cuanto designe expresamente otro efecto que el de nulidad para el caso de contravención". Y asimismo el artículo 1682 CC.: "La nulidad producida por un objeto o causa ilícita, y la nulidad producida por la omisión de algún requisito o formalidad que las leyes prescriben para el valor de ciertos actoso contratos en consideración a la naturaleza de ellos, y no a la calidad o estado de las personas que los ejecutan o acuerdan, son nulidades absolutas". 
Por lo tanto, el contrato de transporte será absolutamente anulable.

b) Embargo posterior al contrato de transporte. En la segunda hipótesis, si una vez celebrado el contrato de transporte, entra a regir una prohibición de comercio o transporte que afecta a la mercancía objeto del contrato, nos enfrentamos ante un impedimento sobreviniente de cumplirlo, que hace imposible su realización, lo que puede configurar un evento de fuerza mayor, de "frustration" o de "restraint of the princess", en los términos que ya hemos analizado en los acápites anteriores. Sin perjuicio de ello, la figura es objeto de una regulación específica en el contrato de transporte marítimo.

En efecto, el artículo IV,2 de las "Reglas de La Haya" ${ }^{51}$ dispone: "Ni el transportador ni la nave serán responsables por pérdida o daño que surja $o$ resulte de: [...] g) Arresto o restricción del principe, gobernantes o de la gente, $o$ embargo bajo un proceso legal".

Consagrando la figura del "restraint of the princess" que analizamos al comienzo de este artículo, se regula específicamente el efecto del embargo que causa la pérdida o daño a la mercancía transportada. Si bien el artículo IV g) regula el caso de pérdida o daño a la mercancía transportada, si ella no se ha dañado, la obligación de transportar y entregar en destino que pesa sobre el transportador se hace legalmente imposible de cumplir, frustrándose el contrato, y liberándose el porteador de responsabilidad por no efectuar el transporte.

En las "Reglas de Hamburgo" (y en el libro III CComCh., que las incorporó) el catálogo de exenciones de La Haya fue sustituido por la fórmula genérica del artículo 984, que señala: "El transportador será responsable de los perjuicios resultantes de la pérdida o del daño de las mercancías, así como del retraso en su entrega, si el hecho que ha causado la pérdida, el daño o el retraso, se produjo cuando las mercancias estaban bajo su custodia en los términos de los articulos 982 y 983, a menos que pruebe que él, sus dependientes o agentes, adoptaron todas las medidas que razonablemente podian exigirse para evitar el hecho y sus consecuencias".

En la legislación chilena, el transportador marítimo se encuentra en una situación análoga a la de un deudor civil, en el sentido que puede eximirse de responsabilidad si prueba que él, sus agentes y dependientes adoptaron todas las medidas razonablemente exigibles para evitar el hecho y sus consecuencias. O sea, establecida su responsabilidad prima facie, pesa sobre el transportador su defensa, o su incumplimiento se presume imputable. En Chile, el transportador marítimo responde de culpa leve, ya que el contrato

51 "Convención de Bruselas para la unificación de ciertas reglas relativas a los conocimientos de embarque" (Bruselas, 1924, las "Reglas de La Haya”) 
de transporte marítimo es un contrato oneroso conmutativo, que se celebra en beneficio de ambas partes: cargador y transportador.

En consecuencia, bien por la vía de acreditar que se adoptaron todas las medidas que eran razonablemente exigibles para evitar el hecho y sus consecuencias, o por la vía del caso fortuito, que a nuestro juicio son análogas, el embargo de la mercancía transportada es una defensa que permite al transportador marítimo eximirse de responsabilidad, en la medida que se cumpla con el test del naviero prudente (en aquélla) o que se configuren los requisitos del caso fortuito (en ésta).

5. En la práctica del negocio marítimo hay cláusulas en los conocimientos de embarque que tratan esta y otras vicisitudes que afectan al contrato de transporte durante su ejecución. Así por ejemplo, en algunos conocimientos de embarque 52 , la "Cláusula de métodos y rutas de transporte", dispone: "9.1. El Transportador puede en cualquier momento y sin aviso al comerciante:/ [...]/ b) transferir las mercancias de un transporte a otro, o transportarlas en un buque distinto al nominado en el anverso o mediante cualquier otro medio de transporte, incluso transbordando o reexpidiéndolas por aquellos medios que no hayan sido contemplados o dispuestos en este conocimiento de embarque; [...]/ d) cargar y descargar las mercancías en cualquier otro lugar o Puerto (sea o no denominado en el anverso como Puerto de Carga o Puerto de Descarga) y almacenar las mercancias en cualquier puerto o lugar, incluyendo pero no limitado al uso de almacenes extra portuarios en cualquier puerto; [...]/ e) cumplir con cualquier orden o recomendación dadas por un gobierno o autoridad o persona que actue a nombre de tal gobierno o autoridad, o que bajo los términos del seguro en cualquier medio de transporte empleado por el transportador tenga el derecho a impartir tales órdenes o instrucciones".

Por su parte, en la "Clausula problemas que afectan adversamente el cumplimiento del transportador", del mismo conocimiento de embar$q^{5} e^{53}$, se dispone en 19.1: "Si en cualquier tiempo el transporte se afecta o es probable que se afecte por un impedimento, riesgo, peligro, demora, dificultad o desventaja de cualquier especie y cualquiera sea la forma que se genere, que no puede ser evitada por el transportador ejerciendo esfuerzos razonables (aun si las circunstancias que causaron tal impedimento, riesgo, peligro, demora,

${ }^{52}$ Hemos tomado como ejemplo el conocimiento de embarque de Mediterranean Shipping Company, disponible en http://www.mscgva.ch/bl_terms, sitio visitado el 1 de octubre de 2014. De un tenor similar son las cláusulas del conocimiento de embarque de Maersk, disponibles en http://www.maerskline.com, visitado en la misma fecha. Ambas corresponden a una traducción libre del autor.

${ }^{53}$ Ibíd., Cláusula 19, que corresponde a la Cláusula 20 del conocimiento de embarque de Maersk. 
dificultad o desventaja existía al tiempo que este contrato se celebró o que las mercancias fueron recibidas para el transporte) el transportador podrá a su sola discreción y sin avisarle al Comerciante, sea que el transporte se haya o no iniciado:/ a) transportar las mercancías al Puerto de descarga contratado o al lugar de entrega, cualsea aplicable, por una ruta alternativa a la indicada en este conocimiento de embarque o la que sea usual para las mercancias consignadas a ese puerto de descarga o lugar de entrega; $[. .$.$] / o b) suspender el transporte$ de las mercancias y almacenarlas en tierra o a flote bajo los términos y condiciones de este conocimiento de embarque y procurar reexpedirlas a la brevedad posible, pero el transportador no hace representación alguna respecto al periodo máximo de suspensión; [...]/ o c) abandonar el transporte de las mercancias y colocarlas a disposición del comerciante en cualquier lugar o Puerto que el transportador considere seguro y conveniente, o desde el cual el transportador no es capaz, usando esfuerzos razonables para continuar el transporte, caso en que la responsabilidad del transportador por esas mercancias cesará. Sin embargo, el transportador estará habilitado para el pago integro del flete respecto de las mercancias recibidas para el transporte, y el comerciante deberápagar cualquier costo adicional incurrido por el abandono de las mercancías. Si el transportador elije usar una ruta alternativa de acuerdo con la Cláusula 19.1 a) o suspender el transporte de acuerdo con la cláusula 19.1 (b) esto no perjudicará su derecho para abandonar posteriormente el viaje.

En 19.2 va prescrito: "Si el transportador elige invocar los términos de la Cláusula 19, entonces sin perjuicio de la Cláusula 9, el transportador tendrá derecho al flete y costo adicional según el transportador lo determine."

En consecuencia, y haciendo uso de las facultades establecidas en estas cláusulas, es probable que el transportador marítimo dé por terminado el viaje en un puerto cercano, que no esté afecto por el embargo, o resuelva restituir la carga al puerto de embarque, o al lugar al cual el cargador le indique.

6. La obligación correlativa del cargador en orden a pagar el flete no se regula en las "Reglas de La Haya" ni en las "Reglas de Hamburgo", pero sí en el libro III CComCh. Recordemos que el contrato de transporte marítimo es un contrato bilateral, entonces, la pregunta es equé sucede con la obligación de pagar el flete, si el transportador no puede llegar con la carga a destino, a consecuencia de una prohibición de comerciar que afecta a la mercancía?

Dispone el artículo $1021 \mathrm{CComCh}$. (en sus incisos pertinentes) lo siguiente: "Por regla general, a menos que se estipule expresamente otra cosa, el flete se gana y será exigible una vez entregadas las mercancias en el destino previsto en el contrato, en alguna de las formas que señalan las letras a), b) o c) del artículo 983. No se deberá flete por las mercancias perdidas por caso fortuito o fuerza mayor. Sin embargo, cuando las mercancias se han perdido 
por un acto o a consecuencia de avería común, se pagará el flete correspondiente como si aquéllas hubiesen llegado a destino. La estipulación de flete pagadero a todo evento, surtirá efecto siempre que la carga se encuentre a bordo y la nave haya iniciado el viaje..."

Del análisis de esta norma se desprenden las siguientes situaciones:

i) Si las mercancías se pierden a consecuencia del embargo, por ejemplo, ellas son confiscadas por la autoridad en el puerto de destino, o en un puerto de tránsito, no se devenga el flete (inciso $2^{\circ}$ ).

ii) Si la pérdida de las mercancías es consecuencia de un acto de avería gruesa, sí hay derecho a cobrar el flete, pero esto supone que se haya configurado una situación de avería gruesa (inciso $2^{\circ}$ ).

iii) Si se ha estipulado un flete pagadero a todo evento (por medio de la cláusula "ship/cargo lost or not lost": nave/carga perdida o no), el flete se devenga una vez embarcada la mercancía y habiendo zarpado el buque, por lo que si el embargo es posterior al zarpe, si se debe el flete (inciso $3^{\circ}$ ).

iv) En los demás casos, si la mercancía no se entrega en destino, producto de un embargo, no hay derecho al pago del flete, puesto que este no se devenga, por así disponerlo el inciso $1^{\circ}$, que contiene la regla general en esta materia.

\section{EMBARGO Y AVERÍA GRUESA}

1. La avería gruesa es una institución única y peculiar del derecho marítimo, que consiste en colectivizar o repartir entre los distintos interesados en la aventura marítima, los efectos de un sacrificio o gasto que se efectúa para salvar a la expedición de un peligro común. El artículo $1095 \mathrm{CComCh}$. dispone: "Constituyen avería gruesa o común los sacrificios o gastos extraordinarios e imprevistos, efectuados o contraidos intencional y razonablemente, con el objeto de preservar de un peligro común a los intereses comprometidos en la expedición maritima".

La causa de la avería gruesa es el peligro común que acecha la aventura marítima, lo que explica y justifica la obligación de los interesados en ella de contribuir a sus efectos. En palabras de Rose: "debe existir un peligro real a la propiedad involucrada en la aventura marítima. Tradicionalmente, esto ha significado una amenaza a la integridad física de los bienes involucrados. Esto se conforma a la noción del derecho Común que la avería gruesa se relaciona a la preservación de la propiedad" 54 .

2. ¿Una prohibición de comerciar constituye un peligro común, que afecta a la totalidad de la expedición marítima?

\footnotetext{
${ }^{54}$ Rose, F. D., General Average: Law and Practice (London, 1997), p. 17.
} 
Bajo la reserva y salvedad de que cada caso concreto debe analizarse aisladamente, en su integridad y a la luz de sus circunstancias particulares, de manera general y abstracta, podemos responder que un embrago no necesaria ni automáticamente constituye un peligro común, ya que no afecta a la integridad de la expedición.

En efecto, el carácter de común de la avería gruesa deriva de que la generalidad de los intereses de la expedición marítima han sido afectados; los intereses que conforman la expedición son, en principio: nave, carga y flete. La regla general es que las prohibiciones de comerciar afectan a las mercancías, no a las naves ni al pago de los fletes, por ende estaríamos en presencia de una avería particular o simple, que debe ser soportada económicamente sólo por la carga, sin derecho a solicitar contribución a los demás intereses de la navegación marítima. Empero, es concebible que existan embargos que sean generales y extensos en su aplicación, y abarquen tanto la proscripción del comercio de ciertas (o todas) las mercancías, como la prestación de servicios a la industria marítima, y los servicios de transporte marítimo, y por ahí podría concebirse una prohibición que afectase a la expedición marítima en su integridad, de manera general, en términos que permitiera calificar al peligro como común.

Lo que a nuestro juicio es más difícil de fundamentar, es postular que una prohibición de índole legal (esto es, la que deriva de una norma jurídica, de aplicación obligatoria y generalizada) pueda importar, per se, un peligro para la expedición marítima. Entendemos que una requisición o confiscación de la nave, carga y el flete, en caso de una guerra, conmoción interna, o un estado de excepción, o la amenaza de ellas, sean un peligro concreto e inmediato para los intereses de una expedición marítima, porque se trata de una pérdida de la tenencia y posesión de tales bienes, o la inminencia de su pérdida. Pero la existencia de una prohibición legal de comerciar y transportar mercancías hacia determinados Estados o zonas no constituye de suyo un peligro concreto o inminente, sólo se trata de una prohibición, y el peligro de la pérdida de la nave o la carga derivaría de su transgresión. Esto acotaría más la posibilidad de configurar un peligro, sólo a los eventos en que la prohibición sea sobreviniente y afecte a las naves que ya navegan dentro de la zona a la que ella se aplica, de suerte que tras la vigencia del embargo, la nave y su carga quedan automáticamente en una situación de infracción a la interdicción de comercio, y por tanto son susceptibles de confiscación o comiso. Pero no ocurre lo mismo si la prohibición rige desde antes del inicio de la aventura marítima y es (o debe ser) conocida por el capitán de la nave, así como por los dueños de la carga, ya que estaríamos en presencia de una infracción que es evitable, y como tal, difícilmente puede configurar un peligro real e inminente a la expedición marítima en curso. 


\section{EMBARGO Y SEgUROS MARÍTIMOS}

Dispone el artículo 1161 CCom: "Por regla general, los seguros maritimos tienen por objeto indemnizar al asegurado respecto de la pérdida o daño que pueda sufrir la cosa asegurada por los riesgos que implica una aventura maritima, fluvial, lacustre, o en canales interiores."

Enseguida, su artículo 1162 prescribe: "La aventura y su extensión dependen de lo que las partes estipulen en el contrato de seguro./ No obstante, a falta de estipulación en contrario, se entienden incluidos en el riesgo los peligros que provengan o que puedan ocurrir como consecuencia de la navegación o de estar la nave o artefacto naval en puerto o detenidos, incluyendo en este concepto los peligros derivados de las condiciones del tiempo, incendio, piratas, ladrones, asaltantes, capturas, naufragios, varamientos, abordajes, cambios forzados de ruta, apresamiento, saqueo, requisamiento por orden de la autoridad administrativa, retención por orden de potencia extranjera, represalia y, en general, todos los casos fortuitos que ocurran en el mar u otros medios. / Cualquier excepción a los riesgos señalados en el inciso anterior, deberá constar expresamente en la póliza."

De acuerdo con los preceptos citados, el embargo comercial, prohibición o interdicción de de comerciar constituye un riesgo de la aventura marítima (fluvial, lacustre o en canales interiores), sea que configure o no un requisamiento por orden de la autoridad administrativa, o una retención por orden de potencia extranjera, en la medida que se cumplan con los requisitos del caso fortuito o fuerza mayor, que hemos analizado en el acápite número 4, y en especial, el que dice relación con la previsibilidad, exigencia que permite determinar la concurrencia o no concurrencia de la fuerza mayor en la especie, pudiendo distinguir las siguientes situaciones:

a) Embargo vigente al inicio de la aventura marítima. Si el embargo existía antes de la celebración del contrato de seguro, o antes del inicio de la aventura marítima, pudo haber sido previsible por las partes contratantes al celebrar el contrato, o al zarpe de la nave, y si las partes de hecho sabían de su existencia, falla el requisito de la previsibilidad del caso fortuito y por ende no concurre el componente incertidumbre del riesgo, en cuanto elemento del seguro marítimo. Ello importa que concurren dos razones poderosas para que el seguro marítimo no lo cubra: porque no es un caso fortuito, y porque no es un evento incierto que constituya un riesgo asegurable.

b) Embargo sobreviniente al inicio de la aventura marítima. Si el embargo sucede al zarpe de la expedición, importa una circunstancia que no era previsible al inicio de la aventura marítima, y es también posterior a la celebración del contrato de seguro marítimo, y en este caso, debería estar cubierto por la póliza, pero si la nave aún no ingresa a la zona del embargo, es 
posible evitar incurrir en infracción del mismo. En este evento, el asegurado tiene el deber de evitar las consecuencias del siniestro, tal como lo ordena el artículo 524 del Código de Comercio, $\mathrm{N}^{\circ}$ 6, que dispone: "Obligaciones del asegurado. El asegurado estará obligado a:/ [...] $6^{\circ}$ En caso de siniestro, tomar todas las providencias necesarias para salvar la cosa asegurada o para conservar sus restos".

Esta obligación (que se denomina "sue and labour"), consiste en que el asegurado debe evitar ingresar a la zona de cobertura territorial del embargo, para impedir que se consume la infracción a la prohibición de comercio, lo que se efectúa desviando la nave, cambiando el puerto de destino del transporte de la mercancía prohibida, o descargándola en un puerto intermedio que no esté afecto a la interdicción, o simplemente no descargándola en el puerto de destino que está proscrito.

En otras palabras, el embargo que es posterior al zarpe de la nave, no necesariamente configura un siniestro para los efectos de la póliza de seguro marítimo.

c) Embargo sobreviniente al inicio de la aventura marítima, con pérdida o daño de la materia asegurada. Esta situación es equivalente a la anterior, pero agrega un elemento más, cual es que efectivamente se infringe el embargo y la materia asegurada (sea nave, carga, contenedor o flete) se pierde por efecto del embargo (mediante confiscación, requisición, decomiso, etc.), lo que configura un siniestro, para los efectos del seguro marítimo.

En todo caso, es conveniente tener presente que se ha fallado por los tribunales ingleses que el uso de la fuerza no es un requisito de la retención, ni se exige que la fuerza haya estado disponible para su uso inmediato $0^{55}$. Tampoco es necesario que exista una privación irremediable de la propiedad de la materia asegurada, de hecho, si transcurre un tiempo sin que el asegurado la recupere, o adquiera certeza acerca de su recupero, puede optar por calificar al siniestro como una pérdida total constructiva o asimilada ${ }^{56}$.

Tratándose de la requisición o "detainment", estas situaciones se cubren por la cláusula adicional de guerra (Institute War Clauses Hull Time 1711/95 e Institute War Clauses Cargo 1/1/82), que amparan las pérdidas y daños causados a la nave o carga asegurada por apresamiento, captura, restricciones o detenciones, o tentativas de ellos y sus efectos.

\footnotetext{
${ }^{55}$ Hodges, S., cit. (n. 18), p. 574.

${ }^{56}$ Barroilhet, C., Derecho del seguro maritimo, cit. (n. 19), p. 174.
} 


\section{BiBLIOGRAFÍA}

Abeliuk Manasevich, René, Las obligaciones ( $3^{a}$ edición, Santiago, Editorial Jurídica de Chile, 1993), II.

BARroilhet, Claudio, derecho del seguro maritimo (Santiago, Librotecnia, 2007).

Boyd, Stewart - Berry, Steven - Burrows, Andrew - Eder, Bernard - Foxton

David - SMITH, Christopher, Scrutton on Charter Parties and Bills of Lading (21 edición, London, Sweet \& Maxwell, 2008).

BRUnetTI, Antonio, derecho maritimo privado italiano (Traducción de R. Gay de Montilla, Barcelona 1950), III.

Colinvaux, Raoul, Carver's Carriage by Sea (12 a edición, London, Steven \& Sons, 1971), I.

Cooke, Julian - Kimball, John - Young, Timothy - Martowsky, David - Taylor, Andrew - Lambert, Le Roy, Voyage Charters (London, Lloyd's of London Press, 1993).

Diccionario de la Lengua Española en http://lema.rae.es/drae

Eyzaguirre EChEVERría, Rafael, Contrato de transporte y nociones de derecho marítimo y aéreo (Santiago, Editorial Jurídica de Chile, 1980).

Hodges, Susan, Cases and Materials on Marine Insurance Law (London, 1999).

López Santa María, Jorge, De los contratos. Parte general (2a edición, Santiago, Editorial Jurídica de Chile, 1998).

O’May, Donald, On Marine Insurance (London, 1993).

Office of Foreign Assets Control, U.S.A., Department of the Treasury, en: http:// www.treas.gov/ofac

Rose, F. D., General Average: Law and Practice (London, 1997).

Ruiz Soroa, José María - Zabaleta, Santiago - González, Manuel, Manual de derecho del transporte maritimo (Vitoria - Gasteiz, 1986).

Simone, Osvaldo Blas, Seguros maritimos (Buenos Aires 2002).

The Common Law Library, Chitty on Contracts (27a edición, London, Sweet \& Maxwell 1994), I. 
